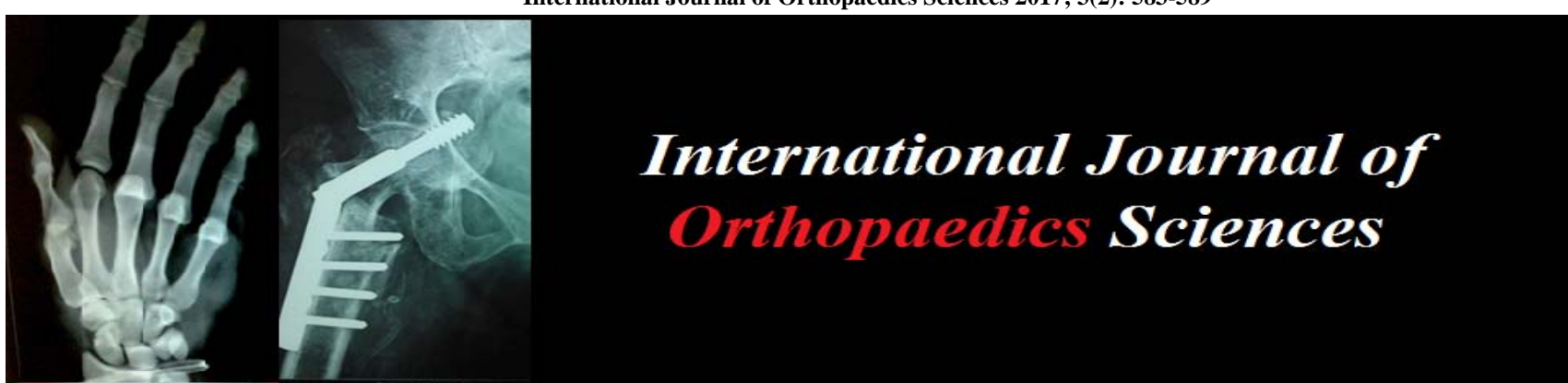

ISSN: $2395-1958$

IJOS 2017; 3(2): 583-589

(C) 2017 IJOS

www.orthopaper.com

Received: 25-02-2017

Accepted: 26-03-2017

Dr. Arvind Kumar SM

Professor, Department of

Orthopaedics PSGIMSR

Coimbatore, Tamil Nadu, India

Dr. N Venkatesh Kumar

Department of Orthopaedics

PSGIMSR Coimbatore,

Tamil Nadu, India

Dr. Udayamoorthy. S

Department of Orthopaedics

PSGIMSR Coimbatore,

Tamil Nadu, India

Dr. Kailash

Department of Orthopaedics

PSGIMSR Coimbatore,

Tamil Nadu, India
Correspondence

Dr. Arvind Kumar SM

Professor, Department of

Orthopaedics, PSGIMSR

Coimbatore, Tamil Nadu, India

\section{Radiological assessment of inter-prosthetic joint movement in bipolar hip hemiarthroplasty for fracture neck of femur}

\author{
Dr. Arvind Kumar SM, Dr. N Venkatesh Kumar, Dr. Udayamoorthy S \\ and Dr. Kailash
}

DOI: http://dx.doi.org/10.22271/ortho.2017.v3.i2f.55

\section{Abstract}

Introduction: Fracture neck of femur has been recognised since the time of Hippocrates and is a common orthopaedic problem in old age and they have a tremendous impact on both the health care system. Despite marked improvements in the implant design, surgical technique and patient care, they still remain an unsolved fracture as for as treatment and results are concerned among the orthopaedic fraternity around the world.

By this study we will be able to assess whether bipolar prosthesis really functions as its name suggests or vice versa as the literature suggests.

Materials and Methods: Consist of 2 parts. Part I is a (prospective study) in which Patients who undergone Bipolar hemiarthroplasty for fracture neck of femur at PSG Hospitals were included in the study after obtaining their consent during the period of December 2011 to June 2013.

Part II was a retrospective study where we took a data of patients who were operated earlier in our institute and had completed atleast 2 years of follow-up.

Results and Discussion: With this study we found that for effective functioning of bipolar prosthesis IPJ movement remains a vital $\operatorname{cog}$ in the success of the bipolar prosthesis. In this study we found that there is good amount Inter-prosthetic joint movement of bipolar prosthesis at short - term and mid - term followup. The functional outcome is also good when Inter-prosthetic joint movement is more than $25 \%$.

Keywords: Neck of femur fracture, bipolar hemiarthroplasty, inter prosthesis joint

\section{Introduction}

Fracture neck of femur has been recognised since the time of Hippocrates and is a common orthopaedic problem in old age and they have a tremendous impact on both the health care system and society in general ${ }^{[1]}$. Despite marked improvements in the implant design, surgical technique and patient care, they still remain an unsolved fracture as for as treatment and results are concerned among the orthopaedic fraternity around the world ${ }^{[2]}$. Fractures of the neck of femur are on increase, which is not unexpected, as the general life expectancy has significantly increased during the few decades. These fractures may double within next 20 years and fracture rate doubles for each decade of life after $5^{\text {th }}$ decade of life ${ }^{[3]}$. It's has been predicted that by the year of 2050, the number of hip fractures would triple.

This is the commonest fracture in old aged individuals because of osteoporosis and advancing age causing more brittleness of bone. So prolonged immobilization during such fractures in elderly will jeopardise the life span of the patient and further complicates the problem. This forces one to totally abandon complete immobilisation to achieve a bony union, or to resort early ambulatory procedures by surgery.

The blood supply to neck and head of femur is extensive, intricate and complicated. Healing process mainly depends on good blood supply. Non-union, avascular necrosis of femoral head and secondary degenerative arthritis are the principal complications of this fracture. The surgeon may have control over the problem of non-union, whereas he may have none over avascular necrosis and arthritis. This further handicaps the treatment of these fractures as the healing process is always in doubt. It's also a known fact that hip is a weight bearing joint and many performance based functions depend on hip joint. A successful operation at hip joint should provide painless, stable hip with wide range of movements. 
Under these circumstances one has to decide whether the prolonged immobilization has to be employed to achieve bony union or quick ambulation by hemi-replacement arthroplasty, to achieve fair degree of function. Since early 1950's prosthetic replacement was introduced for solving the problems of Fracture neck of femur and vitallium intramedullary prosthesis received a hearty welcome, thus preventing Non-union and avascular necrosis. The Austin Moore and Thompson prostheses have been successful implants in treating fracture neck of femur. Disabling pain and acetabular erosions are frequent complications after the use of Moore prosthesis ${ }^{[4]}$. So in an attempt to retard the acetabular wear, prolong the life of the implant and delay the need for revision surgery the bipolar prosthesis was developed by James E Bateman in Toronto in 1974, which had the great advantage of second joint, below the acetabulum. It was named bipolar prosthesis, since it had an outer head of metal which articulates with acetabulum and a second inner metallic head which articulates with High Density Poly-Ethylene (HDPE), lining the inner surface of outer head. So hip motion is to occur at 2 interfaces - primarily at the prosthetic interface and secondarily at the metal - cartilage interface, thus minimising the articular wear. This prosthesis was found to be very useful and results were encouraging ${ }^{[5]}$.

But studies attempting to demonstrate the relative movements at the interfaces have yielded conflicting results. It's known that a friction produces particulate debris from the polyethylene liner and this was thought to be the cause of foreign body reaction causing stiffening up of the interprosthetic joint and also osteolysis and aseptic loosening of the implant. Recent studies have shown that over a variable period of time the bipolar prosthesis will become unipolar functionally due to stiffening up of the inter-prosthetic joint (IPJ).

This study represents the assessment of the inter-prosthetic joint movement in bipolar prosthesis done for fracture neck of femur at 6months and mid-term follow-up by radiological means. By this study we will be able to assess whether bipolar prosthesis really functions as it's name suggests or vice versa as the literature suggests.

\section{Materials and Methods \\ Source of data}

Consist of 2 parts. Part I is a (prospective study) in which Patient's who undergone Bipolar hemiarthroplasty for fracture neck of femur at PSG Hospitals were included in the study after obtaining their consent during the period of December 2011 to June 2013.

Part II was a retrospective study where we took a data of patients who were operated earlier in our institute and had completed atleast 2 years of follow-up.

\section{Method of data Collection}

By Convenient sampling method, the patients undergoing bipolar hemiarthroplasty for fracture neck of femur were assessed radiologically for amount of inter-prosthetic joint motion during post-opeartive period.

\section{Implant used}

- For all patients Life ortho care bipolar prosthesis was used (ISO - 13485 certified company). Implant made of 316 - Stainless steel. Femoral stem length is $150 \mathrm{~mm}$, diameter $-8 \mathrm{~mm}$. Outer head diameter varies from 37 to $53 \mathrm{~mm}$ with $2 \mathrm{~mm}$ increment. Inner prosthetic femoral head diameter was $26 \mathrm{~mm}$ and the lining between outer head and inner head is made of UHMWPE (Ultra High molecular Weight Polyethtylene). Neck shaft angle is 130 degrees. 2 types of prosthesis are available (Fixed only with collar, Modular with or without collar and Extra long stem also available).

- No funding was received from the Implant Company for the purpose of this study.

\section{(Prospective study)}

\section{Pre-operative management}

All patients who are undergoing bipolar hemiarthroplasty for fracture neck of femur are considered for the study after getting a written consent from them. All Patients were adequately worked up before surgery and all patients were taken up for surgery within 72 hours. Certain therapeutic measures such as Deep breathing exercises, Static Quadriceps exercises, ankle pumps were taught to the patient preoperatively. A detailed history about the mode of injury and type of fracture were noted.

\section{Surgical Procedure}

All surgeries were performed on an elective basis using standard aseptic precautions, Surgery was performed under spinal or general anaesthesia. Patient was positioned laterally lying on the unaffected side. For all the patient's lateral approach (Hardinge approach) was used in our series.

\section{Post-operative protocol}

Throughout the post-operative period adequate care was taken to prevent abduction and external rotation of the limb. All patients received Quads strengthening X's and mechanical DVT prophylaxis during immediate post-operative period. All patient's were started on Full weight bearing ambulation as tolerated by the patient. Once initial pain subsided specific Xrays were done to assess the inter-prosthetic joint (IPJ) and outer bearing movement was assessed during immediate postop (24 to 48 hours), at 6 weeks and after 6 months with operated hip in neutral and maximum abducted positions.

\section{X-ray Technique:}

Two A.P x-rays of pelvis were taken. One with limbs in neutral position and neutral rotation and the other $\mathrm{x}$-ray with affected limb in Maximum abduction are taken.

\section{Radiological Assessment}

We followed the method of $\mathrm{p}$ lain radiographs, as described by Bochner et al.

On the X-ray in the neutral position, 3 lines are drawn as follows:

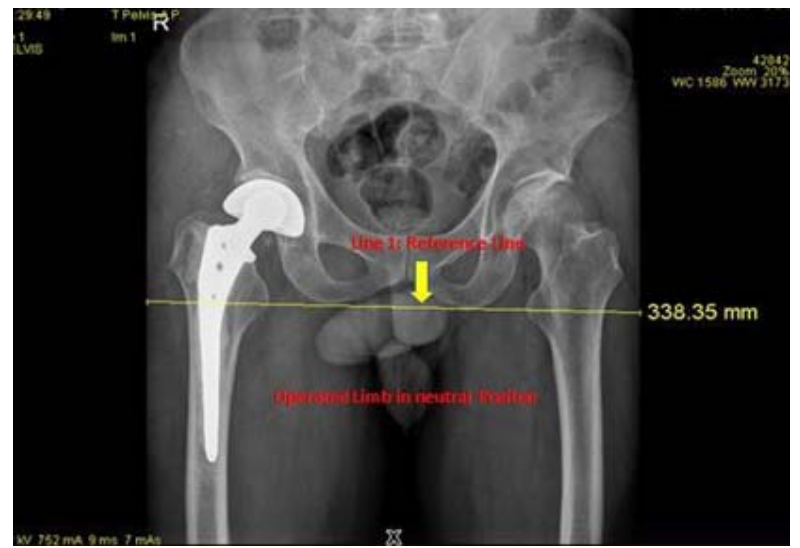

Line 1: a line drawn tangential to the most inferior aspects of the ischial tuberosities which is used as a reference line. 


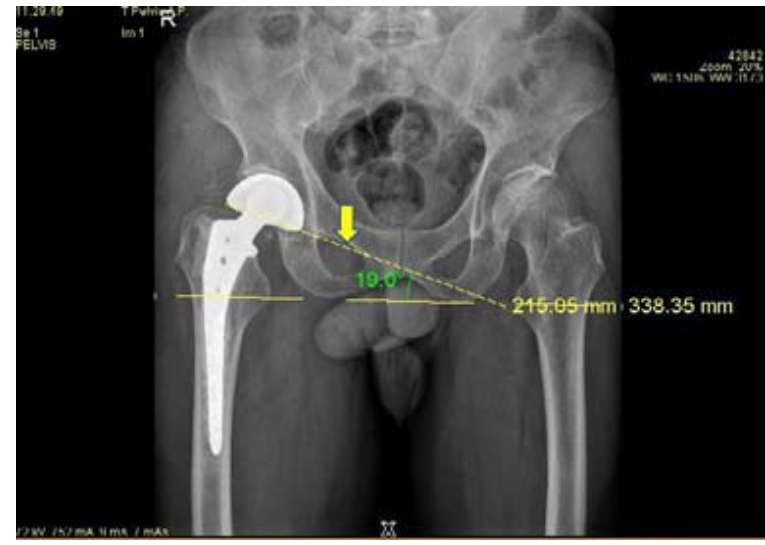

Line 2: drawn along the the inferior margin of the acetabulum

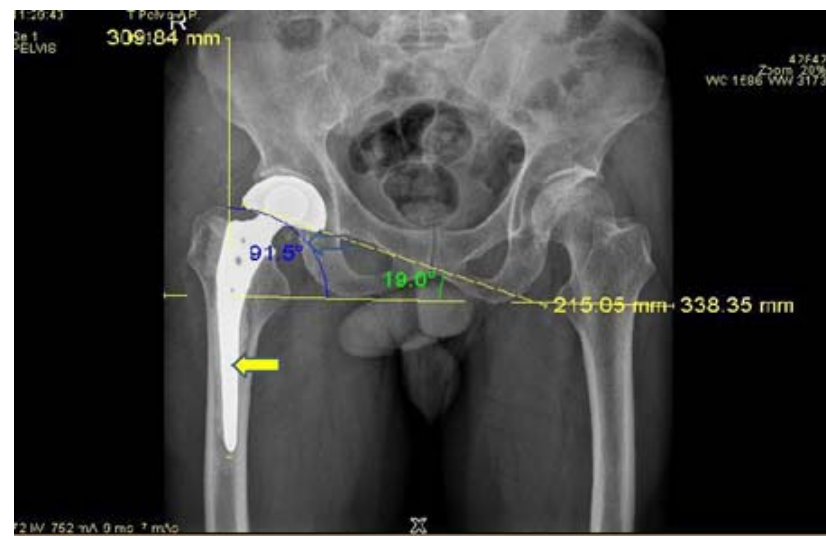

Line 3: Drawn along the centre of the long axis of femoral stem.

- Angle A was defined as the intersection of the line drawn from the inferior margin of acetabular component and the reference line (line of ischial tuberosities).

- Angle B was formed by the intersection of the ischial reference line with a line drawn along the center of the long axis of the femoral stem.

- The same exercise was repeated on the maximum abduction anteroposterior radiograph also and the angles are marked as $\mathrm{A}^{1}$ and $\mathrm{B}^{1}$.

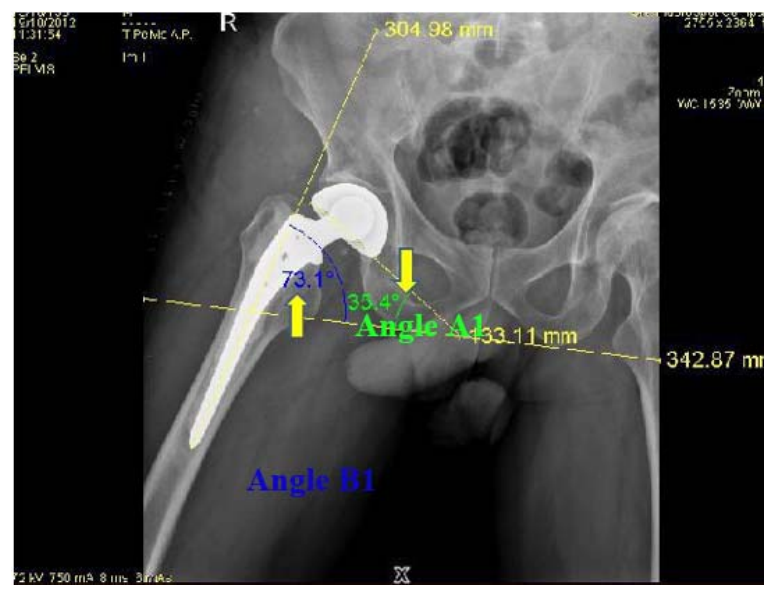

Line 4: Operated Limb in Maximum Abduction

- Now, $\mathrm{B}^{2}$ is the difference between angle $\mathrm{B}$ and $\mathrm{B}^{1}$ which represents the total amount of Hip abduction of the operated limb.

- $\mathrm{A}^{2}$ is the difference between angle $\mathrm{A}$ and $\mathrm{A}^{1}$ which represents the amount of motion taking place between the acetabular component and the acetabulum (Outer bearing interface).

- As we have 2 variables ie. (B2 - total amount of abduction, A2 - motion at the outer bearing interface), the difference between $\mathrm{B}^{2}$ and $\mathrm{A}^{2}$ represents the amount of abduction taking place at the inner bearing (InterProsthetic joint movement).

- Thus the total amount of abduction, movement at outer bearing interface and movement at inter-prosthetic joint were calculated and tabulated for each patient at each follow-up.

X-ray of pelvis with both hips (Abduction of operated hip) with bipolar prosthesis on right side showing Angle A1 - 43.3 and Angle B1 - 74.4 degrees.

$\mathrm{A}=45.1, \mathrm{~B}=83.4, \mathrm{~A} 1=43.3, \mathrm{~B} 1=74.4$ (Degrees)

$\mathrm{B} 2=9$ Degrees (Total Abduction)

A2 =1.8degrees (Motion @ Outer Cup)

$\mathrm{B} 2-\mathrm{A} 2=7.2$ Degrees (Inter-Prosthetic Joint Motion)

A2 =20\% (Motion@ Outer Cup)

$\mathrm{B} 2-\mathrm{A} 2=80 \%$ (Inter-Prosthetic Joint Motion).

At the end of 6 months follow-up, in addition to Radiological assessment Functional outcome was also assessed with Oxford hip score.

Part - 2 (Retrospective study):

Patients in this group who had already undergone Bipolar H.A and completed 2 years follow-up were reviewed. The x-rays were taken in the similar fashion as described above. Functional outcome assessment was done using Oxford hip score. The retrospective study helped us to assess IPJ motion at midterm follow-up.

\section{Oxford Hip Score (OHS)}

- It's useful to assess the outcome after surgical procedures by measuring 'patients' perceptions in adjunction to surgery. OHS assesses pain (6 items) and function (6 items) of the hip in relation to daily activities such as walking, dressing, sleeping etc. 12 items with 5 categories of responses. Scores range from 0 to 4 (worst to best).

- Grading :

- $\quad$-19 $\square$ Worst, May indicate severe hip arthritis, requires some form of surgical intervention.

- 20-29 $\square$ Fair, May indicate moderate to severe hip arthritis. Assessment by X-ray

- 30- $39 \square$ Good, May indicate mild to moderate hip arthritis. Non-surgical treatment, such as exercise, weight loss, and /or anti-inflammatory medication.

- 40-48 Excellent, May indicate satisfactory joint function. May not require any formal treatment. 
Results

Table 1: Radiologically Assessed Total Abduction, Outer Cup Motion And Inter - Prosthetic Joint Motion

\begin{tabular}{|c|c|c|c|c|c|c|}
\hline Duration of & No of & Mean $\mathbf{B}^{2}$ & Mean $\mathrm{A}^{2}$ & Mean $B^{2}-A^{2}$ & Mean $A^{2}$ & Mean $B^{2}-A^{2}$ \\
\hline Follow up & Patient's & (in degrees) & (in degrees) & (in degrees) & (in $\%)$ & (in\%) \\
\hline \multicolumn{7}{|l|}{ Immediate } \\
\hline Post-op & 30 & 18 & 8 & 10 & 45 & 55 \\
\hline 6 weeks & 28 & 23 & 13 & 10 & 57 & 43 \\
\hline 6 months & 30 & 25 & 18 & 7 & 72 & 28 \\
\hline
\end{tabular}

$\mathrm{B}^{2}$ - represents Amount of Total abduction, $\mathrm{A}^{2}$ - represents amount of movement between the outer cup and the acetabulum, $\mathrm{B}^{2}-$ $\mathrm{A}^{2}$ represents amount of IPJ motion.

\section{Oxford Hip Score Vs Age of the Patient}

\begin{tabular}{|c|c|c|c|c|c|}
\hline OHS of Patients of Different Age Gropus & No of Patient's & Mean OHS & STD Deviation & Minimum OHS & Maximum OHS \\
\hline $50-60$ & 7 & 41.5714 & 6.72947 & 32.00 & 48.00 \\
\hline $60-70$ & 9 & 42.0000 & 2.73861 & 39.00 & 48.00 \\
\hline $70-80$ & 12 & 37.0833 & 6.88157 & 26.00 & 46.00 \\
\hline ABOVE 80 & 2 & 37.5000 & 13.00000 & 36.00 & 39.00 \\
\hline TOTAL & 30 & 38.9355 & 7.19692 & 26.00 & 48.00 \\
\hline
\end{tabular}

Table depicts the Oxford Hip score of different age gropus in involving 30 patients of prospective study group, showing decrease in OHS as the age increases. But the decrease in OHS with increasing age group was not statistically significant $(\mathrm{P}=0.062$ ie $>0.05)$.

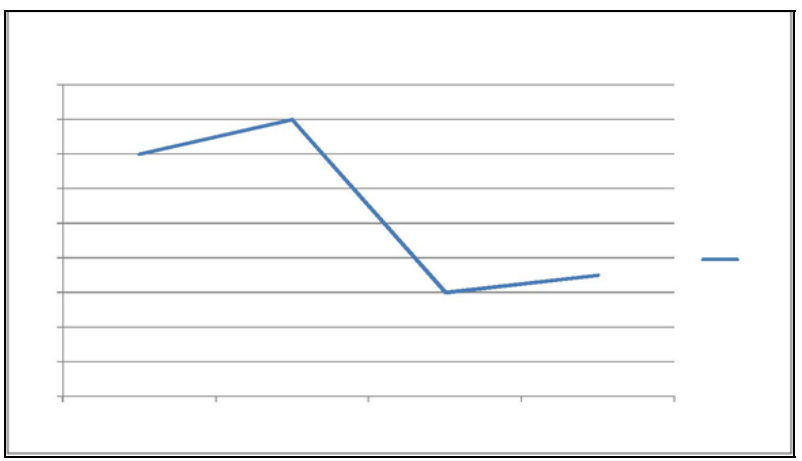

\begin{tabular}{|l|l|l|l|l|}
\hline & & & OHS & \\
\hline 43 & & & & \\
\hline 42 & & 42 & & \\
\hline 41 & 41 & & & \\
\hline 40 & & & & \\
\hline 39 & & & & \\
\hline 38 & & & & OHS \\
\hline 37 & & & \multirow{2}{*}{37} & 37.5 \\
\cline { 2 - 5 } & & & & \\
\hline 36 & & & & \\
\hline 35 & & & & \\
\hline 34 & & & & \\
\hline & $50-60$ & $61-70$ & $71-80$ & $>80$ \\
\hline
\end{tabular}

This graph predicts the decline in the OHS as the age progresses, except for the initial part.

IPJ Motion at 6 Months Vs Age

\begin{tabular}{|c|c|c|c|c|c|}
\hline Age Group & No of Patients & ${\text { Mean } \mathbf{B}^{2}-\mathbf{A}^{\mathbf{2}}}$ & STD. Deviatio & Min & Max \\
\hline & & & $\mathbf{N}$ & & \\
\hline $50-60$ & 7 & 27.8571 & 8.31522 & 14.00 & 38.00 \\
\hline $60-70$ & 9 & 30.1111 & 5.30199 & 25.00 & 39.00 \\
\hline $70-80$ & 12 & 28.6667 & 6.31497 & 18.00 & 38.00 \\
\hline Above 80 & 2 & 35.5000 & .70711 & 35.00 & 36.00 \\
\hline Total & 30 & 29.3667 & 6.38146 & 14.00 & 39.00 \\
\hline
\end{tabular}

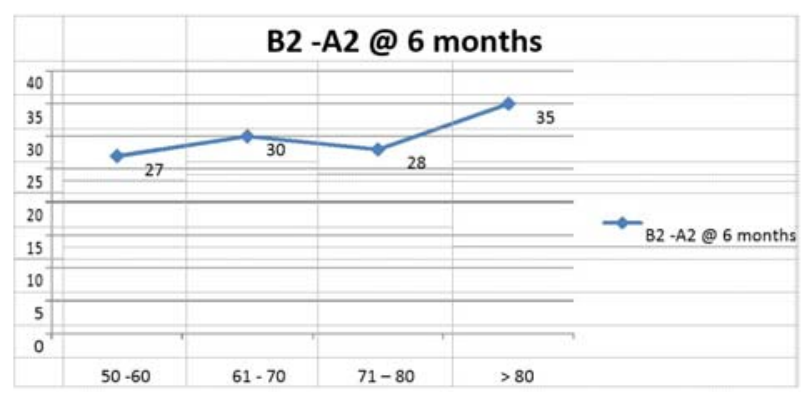

Table 10 shows the IPJ motion at end of 6 months in various age groups in prospective study of 31 patients. On data analysis there was no statistical significance between the IPJ motion and various age groups $(\mathrm{P}=0.495>0.05)$. Though the IPJ motion seems to be higher in patients above 80 years, the sample size for the particular age group was not significant.

This graph demonstrates the relation of $\mathrm{B}^{2}-\mathrm{A}^{2}$ in various age groups. 


\begin{tabular}{|c|c|c|c|c|c|}
\hline Sex & No Of & Mean & Std. & Minimu & Maximu \\
\hline Distribution & Patients & OHS & Deviation & m & m \\
\hline Male & 18 & 38.5263 & 7.99561 & 28.00 & 48.00 \\
\hline Female & 12 & 39.5833 & 5.99179 & 26.00 & 48.00 \\
\hline Total & 30 & 38.9355 & 7.19692 & 16.00 & 48.00 \\
\hline
\end{tabular}

Table 12 depicts the comparison of B2 - A2 at 6 months against the gender in prospective study of 30 patients. The IPJ motion was found to be almost the same in both females and males. There was also a statistical difference between the 2 groups in relation to IPJ motion IPJ.

\section{Motion At 6 Months Vs Oxford Hip Score}

\begin{tabular}{|c|c|c|c|c|c|}
\hline B2 - A2 At 6 Months & No Of Patients & Mean OHS & Std. Deviation & Minimum OHS & Maximum OHS \\
\hline More than & & & & & \\
\hline $25 \%$ & 20 & 42.7000 & 3.21346 & 38.00 & 48.00 \\
\hline Less than $25 \%$ & 10 & 33.7000 & 5.51866 & 26.00 & 41.00 \\
\hline Total & 30 & 39.7000 & 5.90237 & 26.00 & 48.00 \\
\hline
\end{tabular}

Table 1.3 depicts the comparison of IPJ motion at 6 months with Oxford Hip Score in prospective study of 30 patients. IPJ motion of the patients was divided into 2 groups for the ease of data analysis (Group I - IPJ motion $>25 \%$, Group II - IPJ motion $<25 \%$ ). Based on our data analysis the mean OHS was statistically significant in patients with IPJ motion $>25 \%$ (Mean OHS -42.7$),(P=0.00<0.05)$.

\section{Retrospective Study IPJ Motion}

\begin{tabular}{|c|c|c|c|c|}
\hline No of Patients & Mean B2 - A2 & Std. Deviation & Min & Max \\
\hline 10 & 31.0000 & 10.36018 & 15 & 50 \\
\hline
\end{tabular}

Table shows the Mean IPJ motion of 31 degrees in the retrospective study.

\section{Retrospective Study - Oxford Hip Score}

\begin{tabular}{|c|c|c|c|}
\hline No of Patients & Mean OHS & Min & Max \\
\hline 10 & 38.1 & 28 & 44 \\
\hline
\end{tabular}

Table shows Oxford hip score of retrospective study of 10 patients with mean OHS -38.1 .

Retrospective Study - IPJ Motion in \% Vs OHS

\begin{tabular}{|c|c|c|c|c|}
\hline $\begin{array}{c}\text { B2-A2 at time of } \\
\text { follow up }\end{array}$ & $\begin{array}{c}\text { No of } \\
\text { patients }\end{array}$ & $\begin{array}{c}\text { Mean } \\
\text { OHS }\end{array}$ & $\begin{array}{c}\text { Min } \\
\text { OHS }\end{array}$ & $\begin{array}{c}\text { Max } \\
\text { OHS }\end{array}$ \\
\hline$>25 \%$ & 8 & 39.625 & 35 & 44 \\
\hline$<25 \%$ & 2 & 32 & 28 & 36 \\
\hline Total & 10 & 38.1 & 28 & 44 \\
\hline
\end{tabular}

Table shows comparison between the IPJ motion and OHS in Retrospective Study. Since the sample size is small in retrospective study this data was not compared with the data in the Prospective study. For the current retrospective data the analysis was not statistically significant.

\section{Discussion}

The basic advantage of the Bipolar prosthesis over conventional unipolar prosthesis is movement at the two interfaces ie. Between the prosthetic inner femoral head and polyethylene liner and between acetabulum and the outer head. It was proposed that the complications like acetabular erosions would be delayed or prevented by reducing wear due to sliding motion in the acetabular socket. The high molecular weight polyethylene (HMWPE) articulation also absorbs some of the impact forces during gait. This advantage of
Bipolar over unipolar prosthesis has been accepted by many studies, but there have been some reports in the literature that cast doubt on the continuity of inter-prosthetic movement in a bipolar prosthesis over time. Various radiographic studies have been done in which the prosthesis was imaged in various non-weight-bearing and static weight-bearing positions to estimate the fraction of movement that is occurring at the inter-prosthetic joint in a bipolar prosthesis. Phillips ${ }^{63}$ used radiograph in supine position, first in neutral and then in maximum abduction and adduction.

Verberne used image intensifier to do radiological examination. In this context we undertook the present study of evaluating the IPJ motion radiologically over a period of time at 6 months and at the end of 2 years. We had also tried to corelate the amount of IPJ movement to Functional outcome to assess whether there's any improvement in the quality of life in patient's with good IPJ motion. We followed the method of plain radiographs, as described by Bochner et al. In our series the amount of IPJ movement was 55\% during immediate post-op, $43 \%$ during 6 weeks \& $28 \%$ at the end of 6 months. The mean Inter - prosthetic joint movement at end of 2 years follow - up was $31 \%$ for patients in the retrospective group. So at the end of 6 months $66 \%$ of the patients had $>25 \%$ of Inter prosthetic joint movement in our prospective study and $80 \%$ had $>25 \%$ in the retrospective study. However we are not analyzing the same group of patients in the prospective and retrospective study $\&$ the sample size of retrospective study is small. This could have probably resulted in higher inter - prosthetic joint movement at the end of 2 years. Drinker and Murray reported that although some inner motion occurred in most implants, it was less than predicted. Philips TW (1987) had done a study on Fluroscopic movement in 100 patients who had undergone Bateman Bipolar arthroplasty. Out of these 100 patients Group I had 76 patients with arthritis of hip and Group II had 24 patients with neck of femur fractures. In $80 \%$ of group I patients, the prosthesis retained Bipolar function at the end of 4 years follow-up study as compared to only $25 \%$ of group II patients retained the bipolar functioning of the prosthesis.

Verbene G.H.M (1983), did a radiological study of movements of two components in Variokopf prosthesis in 20 patients with fracture neck of femur during Immediate, 1 month and 3 months post-operative period. He observed that the IPJ lost mobility and at 3 months it became almost completely stiff with inter-prosthetic joint motion of only $16.9 \%$ being retained. 
Bochner RM, in a study 26 patients with Bateman's Prosthesis who were assessed radiologically for interprosthetic joint motion, concluded that bipolar function was retained at the end of 4 years and the motion was shared between both the joint interfaces ${ }^{43}$. In their study the interprosthetic joint motion at 6 months was 19\%. In a study conducted Anil kumar rai, from Banaras hindu university, varanasi, india during the period march 2003 to january 2011 treated with BHU bicentric bipolar prosthesis, showed that in cases of fracture neck of femur, the percentage of total abduction occurring at the interprosthetic joint at 3 months was $33.74 \%$ (mean value of all the patients), which fell to $25.66 \%$ at 1.5 years and remained stationary till 6 years. So they concluded that some amount of IPJ motion is still preserved at the time of their mid-term follow-up of 6 years. Higher Inter-prosthetic joint motion was observed in the arthritic group as compared to fracture group. This could be explained possibly due to friction phenomenon.

The results of our study regarding the Inter - prosthetic joint movement was comaparable to other studies in literature. Verbene et al. showed only $16.9 \%$ inter-prosthetic Joint movement at the end of 3 months in 20 patients \& Bochner et al. showed $19 \%$ movement at the end of 6 months in 18 patients. Our study had better inter-prosthetic joint movement of $28 \%$ at end 6 months. This result probably could have been due to lower sample size of the above 2 studies.

Factors Influencing the Inter - prosthetic Joint movement 1. Condition of the Acetabulum: In patients with normal articular cartilage of acetabulum, the outer cup probably. slides more when compared patients with arthritis. This can probably due to friction at which the primary movement occurs in IPJ. Only at the terminal range of movements prosthetic femoral head impinges on the neck leading to movement of the outer cup.

2. The Inner femoral head size used by Verbene et al was
$32 \mathrm{~mm}$ which could have probably decreased the IPJ motion, when compared to Bochner and Philips et al where they.used $22 \mathrm{~mm}$.inner femoral head. In the study done by Philips TW they had suggested that lower the femoral prosthetic head size, then lower will be the friction between the Polyethylene liner \& femoral head \& decreased stress on outer metal cup, which will result in lower acetabular erosions.

3. In previous studies they had used prosthesis with High density polyethylene which is prone for formation of wear debris over time, which could have possibly played a role in decreasing the IPJ motion. The wear debris formed from UHMWPE is much lower than the HDPE used in those days which could have contributed to better IPJ movement.

4. Since in our study we had used Bipolar prosthesis consisting of UHMWPE liner \& optimum size prosthetic Femoral Head, our patients had better inter-prosthetic joint movement when compared with Verberne et al. \& Bochner et al. we also assessed the age of the patient co relating with Inter -prosthetic joint movement, but we did not find any statistical signifance.

\section{Assessment of Functional Outcome Using Oxford Hip Score and It's Co-Relation with IPJ Motion}

Various criteria were used to assess the functional results following bipolar hemiarthroplasty. How best the patient is returned to the pre-fracture status has been the main criteria. In India our customs demand Squatting and sitting cross leged without difficulty. To achieve this patient should have good range of flexion, abduction, adduction and external roation at the hip and full flexion at the knee. Our final results at 6 months after bipolar hemiarthroplasty in our series were analyzed using Oxford Hip Score. The results were compared with the available western and Indian series where bipolar hemiarthroplasty was done for neck of femur patients.

\begin{tabular}{|c|c|c|c|c|c|}
\hline Investigator & No of patients & Excellent & Good & Fair & Poor \\
\hline Hinchey (1976) & 225 & 52.4 & 20.4 & 10.7 & 16.4 \\
\hline Saxena and saraf $(1978)^{76}$ & 82 & 46.1 & 44.8 & 6.5 & 2.6 \\
\hline Mukeherjee and Puri (1986) & 55 & 29 & 49 & 18 & 4 \\
\hline Bavadekar and Manelkar (1987) & 328 & 60 & & 30 & 10 \\
\hline Arvade (1987) & 104 & 70 & & 16 & 14 \\
\hline Our series (2012 -13) & 40 & 56 & 32 & 10 & 2 \\
\hline
\end{tabular}

His table depicts the percentage of functional results following bipolar arthroplasty done for fracture neck of femur.

The difference between excellent and good results are minimal and therefore they can be gropued together as satisfactory results. In the series above Hinchey had $72.8 \%$, Saxena ${ }^{76}$ 90.9\%, Mukerjee and Puri 78\%, Bavedekar 60\% satisfactory results were achieved. In out series satisfactory results were achieved in $88 \%$ of our cases. Only $2 \%$ of the patients had poor results due to moderate /marked pain.

We found that there was no stastistical significance in between the age, sex Vs OHS. However we were able to analyse the relation between the IPJ motion and OHS. We found that there was significant increase in OHS in patients with IPJ motion of more than $25 \%$. So we conclude that more the amount of IPJ motion preserved better will be the functional outcome in patients with bipolar arthroplasty done for femoral neck fractures

\section{Conclusion}

With this study we found that for effective functioning of bipolar prosthesis IPJ movement remains a vital $\operatorname{cog}$ in the success of the bipolar prosthesis. In this study we conclude that: There is good amount Inter-prosthetic joint movement of Bipolar prosthesis at short - term and mid - term follow-up. The functional outcome is also good when Inter-prosthetic joint movement is more than $25 \%$.

\section{Limitations of the Study}

- In this study the patients in the prospective and retrospective are not the same. And hence the results show a trend rather than being specific.

- Sample size is small

- Long term studies are required 


\section{References}

1. Mark F, Smionthloski et al. Current concepts of Intracapsular fracture of Hip. JBJS. 1994; 76A:129-135.

2. Terry Cannole, Ed: Campbell's Operative orthopaedics, $10^{\text {th }}$ edition: Missourie; Mosby -year book. 1998, 339-40.

3. Rockwood, Charles A, et al. Rockwood and green's fracture in Adults $6^{\text {th }}$ edition: Philadelphia, Lipincott raven publishers. 1996, 1693.

4. Johnson CE, Ripley LP, Bray CB, et al. Primary endoprosthetic replacement for acute Neck of femur fractures: A review of 150 cases. Clin. Orthop. Of North America. 1982; 167:123-130.

5. Bateman JE. Single assembly THA, Prelimnary report. Orthop Digest. 1974; 15:35-43.

6. Badgley C. Treatment of displaced subcapital femoral neck fractures in aged with immediate replacement arthroplasty (discussion). JBJS. 1961; 43B:606.

7. Carnesale PG, Anderson LD. primary prosthetic replacement for femoral neck fractures. Arch Surg. 1975; 110:27-29.

8. Chandler SB, Kreuscher PM. A study of the blood supply of the Ligamentum teres and it's relation to circulation of head of femur. JBJS. 1932; 14:834-846.

9. Garden RS, Praston. The structure and function of the proximal end of femur. JBJS. 1961; 43B:577-582.

10. Schek M. the significance of posterior comminution in femoral neck fractures. Clin. Orhop. 1980; 152:138-142.

11. Cane JM, Sulco TP, Zolan S. Treatment of pathological fractures of hip by endoprosthetic replacement. JBJS. 1980; 62A:954-959.

12. Crack HV. An atlas of the arterial supply of the head and neck of femur in man. Clin. Orthop. 1980; 152:17-28.

13. Boyd HB, Salvatore JE. Acute fractures of the femoral neck: Internal fixation or prosthesis? JBJS. 1964; 46A:1066-1068.

14. Arvade DJ. A review of internal fixation and prosthetic replacement for fresh femoral neck fractures. Clin Orthop. India. 1987; 1:77-82.

15. King D. primary prosthetic replacement in frash femoral neck fractures. JBJS. 1964; 46A:260.

16. Hey-grooves EW. Treatment of the fractured neck of femur with special regard to results. JBJS. 1930; 12:1-14.

17. Johnson JTH, Gothers O. Nailing Vs Prosthesis of femoral neck fractures. JBJS. 1972; 57A:686-792.

18. Arnold WD, Lyden JP, Minkoff J. Treatement of intracapsular fractures of femoral neck. JBJS. 1974; 56A:254-262.

19. Arnold CC, Lemperg RK. Fractures of femoral neck. Clin Orthop. 1977; 129:217-222.

20. Brown JT, Alrami G. Transcervcial femoral fractures. JBJS. 1964; 46B:648-663.

21. Mohandas PVA, Anadhi CP. Prosthetic replacement in the treatment of femoral neck fractures. Indian Journal of Orthopaedics. 1977; 11(1):31-37.

22. Austin T Moore. Discussion on femoral head prosthesis. JBJS. 1965; 47A:43.

23. Austin T Moore. The self-locking metallic hip prosthesis. JBJS 1957; 39A: 811 -27.

24. Peter Cordasso. Evolution of treatment of femoral neck fractures. Arch Surg. 1972, 37. 